\title{
Impact of the fear of catching COVID-19 on mental health in undergraduate students: A Predictive Model for anxiety, depression, and insomnia
}

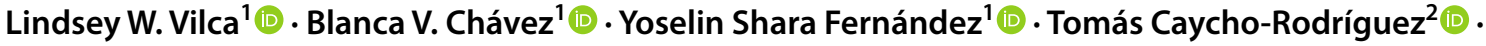 \\ Michael White ${ }^{3}$ (D)
}

Accepted: 16 November 2021

(c) The Author(s), under exclusive licence to Springer Science+Business Media, LLC, part of Springer Nature 2021

\begin{abstract}
Most studies only describe mental health indicators (anxiety, depression, insomnia, and stress) and the risk factors associated with these indicators during the pandemic (sex, student status, and specific physical symptoms). However, no explanatory studies have been found that assess the impact of variables associated with COVID-19. Against this background, the objective of the study was to evaluate the impact of the fear of catching COVID-19 on the level of anxiety, depression, and insomnia in 947 university students of both sexes (41.6\% males and 58.4\% females) between the ages of 18 and $35(M=21.6 ; S D=3.4)$. The Fear of catching COVID-19 Scale, the Generalized Anxiety Disorder Scale (GAD-7), the Patient Health Questionnaire (PHQ-9), and the Insomnia Severity Index (ISI) were used to measure the variables. The results of the study show that the fear of catching COVID-19 significantly influences the level of anxiety $(\beta=.52 ; \mathrm{p}<.01)$, insomnia $(\beta=.44 ; \mathrm{p}<.01)$, and depression $(\beta=.50 ; \mathrm{p}<.01)$ experienced by university students $(\chi 2=2075.93 ; \mathrm{df}=371 ; \mathrm{p}=.000 ;$ RMSEA $=.070$ [CI 90\% .067-.073]; $\mathrm{SRMR}=.055 ; \mathrm{CFI}=.95 ; \mathrm{TLI}=.94)$. The descriptive results show that a notable percentage of university students present significant symptoms of anxiety (23\%), depression (24\%), and insomnia (32.9\%). It is concluded that the fear of catching COVID-19 is a serious health problem since it influences the appearance of anxiety, depression and insomnia symptoms.
\end{abstract}

Keywords Fear of catching COVID-19 · COVID-19 · Anxiety · Depression · Insomnia · Undergraduate students · Predictive Model

\section{Introduction}

The SARS-CoV-2 (COVID-19) pandemic is the largest public health emergency the world has ever faced in recent memory. Various studies have described the mental health problems associated with this pandemic in different groups such as healthcare workers (Muller et al., 2020), clinic patients (Hu et al., 2020), adults (Wang et al., 2020; Xiong et al., 2020), police (Caycho-Rodríguez et al., 2020), school

Lindsey W. Vilca

lwquiro@gmail.com

1 Departamento de Psicología, Universidad Peruana Unión, Lima, Perú

2 Facultad de Ciencias de la Salud, Universidad Privada del Norte, Lima, Perú

3 Dirección General de Investigación, Universidad Peruana Unión, Lima, Perú children (Chen et al., 2020), and university students (Khan et al., 2020). In this context, university students are a particularly vulnerable group to develop mental health problems, such as depression, anxiety (Auerbach et al., 2019), and insomnia (Sivertsen et al., 2018) since they are generally in a transition stage in their academic, professional and personal life (Acharya et al., 2018; Zivin et al., 2009). Added to this, the closure of universities, social isolation, the switch to virtual learning platforms, difficulties in accessing technology, economic problems, and family members' deaths due to COVID-19 have exacerbated the risk of suffering mental health issues.

A study carried out in China on medical students reported that $21.3 \%$ of those surveyed experienced moderate anxiety (Cao et al., 2020). Another longitudinal study, also conducted in China, estimated a prevalence of $12.4 \%$ and $16.8 \%$ for anxiety and insomnia respectively in university students (Ge et al., 2020). Similarly, another study conducted in China on university students from the arts and humanities 
areas evidenced significantly higher anxiety scores than the national average (Wang \& Zhao, 2020). In Bangladesh, a study reported that $33.3 \%$ of university students surveyed experienced anxiety and $46.9 \%$ experienced depression (Khan et al., 2020). Similarly, another study in New Jersey reported high levels of anxiety and depression (Kecojevic et al., 2020). In Germany, a study showed that $35.9 \%$ of university students evaluated had a moderate to severe level of depression, and $27.7 \%$ reported moderate to severe anxiety symptoms (Karing, 2021). Studies carried out in France also showed that university students experienced a significant increase in anxiety and stress during confinement (Essadek \& Rabeyron, 2020; Husky et al., 2020). Another study in Argentina reported that $23 \%$ of the university students evaluated had moderate insomnia and $4 \%$ severe insomnia (Scotta et al., 2021). In Peru, a study carried out on dentistry students showed that $47.4 \%$ had moderate anxiety, and $8.4 \%$ had severe anxiety (Cayo-Rojas et al., 2021). In previous epidemics, acute infectious diseases such as SARS and H1N1 were also associated with high levels of anxiety, depression, and stress in the university population (Main et al., 2011; Wu et al., 2005a, b).

Against this backdrop, the review of the scientific literature reported some limitations in studies conducted in university populations. First, most studies only describe mental health indicators (anxiety, depression, insomnia, and stress) and the risk factors associated with these indicators during the pandemic (sex, student status, specific physical symptoms, and self-rated health status). However, no explanatory studies have been found that assess the impact of variables associated with COVID-19, such as fear or concern about its contagiousness. Second, no explanatory studies assessing the impact of variables associated with COVID-19 on mental health status have been found in the Latin American region, despite the fact that to date, as of the time of the submission of this article, there are 71,055,452 confirmed cases of COVID-19 in the Americas, the region with the highest infection rates (World Health Organization, 2020). Fourth, no reports were found regarding the level of anxiety, depression and insomnia in undergraduate students in the Latin American region.

In this context, it is essential not only to collect information on the rates of anxiety, depression, and other mental health indicators but also to determine causal mechanisms that explain mental health problems during and after the pandemic (Holmes et al., 2020). Especially in vulnerable groups like university students.

Concerning this, no theoretical models have been found to explain emotional reactions during pandemics (Taylor, 2019). However, a definition has recently been proposed that attempts to explain the fear of COVID-19. This construct called coronaphobia is defined as the intense fear of catching COVID-19, which causes a physiological response (palpitations, tremors, shortness of breath, dizziness, change in appetite, and sleep) accompanied by catastrophic thoughts that trigger emotional responses such as sadness, guilt, and anger. All this causes avoidance behaviors that interfere with the person's quality of life (Arora et al., 2020). Therefore, to measure the state of mental health, three principal indicators usually reported in the scientific literature will be used: anxiety, depression, and insomnia (Korkeila et al., 2003; Lin et al., 2020; Pigeon et al., 2017). Based on the exposed gaps in the literature, this study aims to (a) measure the levels of fear of catching COVID-19, anxiety, depression, and insomnia in university students and any possible differences depending on gender and (b) assess the impact of the fear of catching COVID-19 on the level of anxiety, depression, and insomnia in undergraduate students.

\section{Method}

\section{Participants}

A non-probability sample was used for data collection, employing the following inclusion criteria: (a) informed consent of participants, (b) no more than 40 years old, (c) ability to read and write in Spanish, (d) being enrolled in a university program. A sample of 947 Peruvian undergraduate students of both sexes (41.6\% males and $58.4 \%$ females) between 18 and 35 years old was collected $(M=21.6$; $S D=3.4)$. The professional careers most studied by the university students in the sample were psychology (49.8\%), food engineering (12.5\%), and communication sciences (6\%). The study was carried out in three cities in Peru: Lima, Tarapoto, and Juliaca.

\section{Instruments}

\section{The Fear of Catching COVID-19 Scale}

Created by Caycho-Rodríguez et al. (2021) with the objective of evaluating the concern about the spread of COVID-19 and the impact that this concern can have on people's daily functioning (specifically on their mood and their ability to carry out their daily activities). It is made up of six items that have four response options $(1=$ Never or rarely to $4=$ Nearly all the time), where high scores indicate more frequent concern. In the present study, the one-dimensional model presented adequate indices of reliability $(\alpha=0.92 ; \omega=0.89)$ and validity based on internal structure $(\chi 2=163.76$; $\mathrm{df}=9 ; \mathrm{p}=0.000 ; \mathrm{CFI}=0.99 ; \mathrm{TLI}=0.98 ; \mathrm{RMSEA}=0.131$; SRMR $=0.037$ ). 


\section{Generalized Anxiety Disorder Scale (GAD-7)}

Developed by Spitzer et al. (2006) and adapted to Spanish by García-Campayo et al. (2010), this scale is made up of seven items that have four response categories ranging from "never" (0) to "almost every day" (3), where a higher score indicates a greater presence of the disorder. A cut-off point of 10 points was used to assess the presence of significant symptoms of generalized anxiety disorder (García-Campayo et al., 2010). In the present study, the one-dimensional model presented adequate indices of reliability $(\alpha=0.93 ; \omega=0.89)$ and validity based on internal structure $(\chi 2=174.73$; $\mathrm{df}=14 ; \mathrm{p}=0.000 ; \mathrm{CFI}=0.99 ; \mathrm{TLI}=0.99 ; \mathrm{RMSEA}=0.107$; $\mathrm{SRMR}=0.033$ ).

\section{Patient Health Questionnaire (PHQ-9)}

Developed by Spitzer et al. (1999) and adapted into Spanish by Zhong et al. (2014), this questionnaire consists of nine items that have four categories ranging from "not at all" (0) to "almost every day" (3). A 10-point cut-off point was used to assess the presence of significant symptoms of depression (Manea et al., 2012). In the present study, the onedimensional model presented adequate indices of reliability $(\alpha=0.92 ; \omega=0.90)$ and validity based on internal structure $(\chi 2=132.39 ; \mathrm{df}=27 ; \mathrm{p}=0.000 ; \mathrm{CFI}=0.99 ; \mathrm{TLI}=0.98$; RMSEA $=0.062 ;$ SRMR $=0.032$ ).

\section{Insomnia Severity Index (ISI)}

Developed by Bastien et al. (2001) and adapted into Spanish by Fernandez-Mendoza et al. (2012), this instrument consists of seven items that have five response categories ranging from "nothing" (0) to "very much" (4). A 10-point cut-off was used to assess the presence of significant symptoms of insomnia (Morin et al., 2011). In the present study, the one-dimensional model presented adequate indices of reliability $(\alpha=0.88 ; \omega=0.91)$ and validity based on internal structure $(\chi 2=503.58 ; \mathrm{df}=14 ; \mathrm{p}=0.000 ; \mathrm{CFI}=0.94$; $\mathrm{TLI}=0.91 ;$ RMSEA $=0.187 ;$ SRMR $=0.072$ ).

\section{Procedure}

For this study, the approval of the ethics committee of the Center for Research and Innovation in Health (CIISA) of the Universidad Peruana Unión and was obtained and the standards of the Declaration of Helsinki (Rickman, 1964; World Medical Association, 2013) were met. The data collection was done through a virtual form, using the digital platform Google Forms. In the first part of the virtual form, the objectives of the study were explained, the time required to complete the form was presented and informed was requested, where the confidentiality of the information was assured with the assurance that the participants could withdraw at any time. Only participants who gave their informed consent could complete the following sections of the form. The virtual form was applied during the virtual classes of the university students, and it was also sent to their emails.

\section{Data Analysis}

For the Structural Equation Model (SEM) the WLSMV estimator was used and to evaluate the adjustment of the proposed model the CFI $(>0.90)$, TLI $(>0.90)$, RMSEA $(<0.08)$ and SRMR $(<0.08)$ coefficients were used. In order to evaluate the adjustment indexes, the criteria proposed by Kline (2015) and Schumacker and Lomax (2015) were used. As for the measurement models, a Confirmatory Factor Analysis (CFA) was carried out using the WLSMV estimator and the adjustment indicators carried out in the SEM model were taken into account.

The lavaan package (Rosseel, 2012) was used for the Structural Equation Model (SEM), the semTools package (Jorgensen et al., 2018) for factorial invariance and the ggstatsplot package (Patil, 2018) for the comparative analysis by sex. For all statistical analyses, the RStudio environment was used (RStudio Team, 2018) for R (R Core Team, 2019).

\section{Results}

\section{Descriptive Analysis of Anxiety, Depression and Insomnia in University Students}

Table 1 shows that $23 \%$ of university students presented significant symptoms of anxiety. Similarly, 24\% and 32.9\% showed significant symptoms of depression and insomnia, respectively.

\section{Fear of Catching COVID-19 Based on Sex}

Before performing the comparative analysis, the factorial structure of the scale was verified to be invariant for the groups of men and women in the sequence of invariance models proposed: metric $(\Delta \mathrm{CFI}=-0.002)$, scalar

Table 1 Descriptive analysis of anxiety, depression and insomnia

\begin{tabular}{llllll}
\hline & \multicolumn{3}{l}{$\begin{array}{l}\text { Absence / Minimal symp- } \\
\text { toms }\end{array}$} & & \multicolumn{2}{l}{$\begin{array}{l}\text { Significant symp- } \\
\text { toms }\end{array}$} \\
\cline { 2 - 3 } \cline { 6 - 6 } \cline { 6 - 6 } & $\mathrm{n}$ & $\%$ & & $\mathrm{n}$ & $\%$ \\
\hline Anxiety & 729 & $77 \%$ & & 218 & $23 \%$ \\
Depression & 720 & $76 \%$ & & 227 & $24 \%$ \\
Insomnia & 635 & $67.1 \%$ & & 312 & $32.9 \%$ \\
\hline
\end{tabular}


$(\Delta \mathrm{CFI}=-0.003)$ and strict invariance $(\Delta \mathrm{CFI}=0.001)$. No significant difference was found in men's $(M=5.51$, $D S=3.77)$ and women's $(M=5.74, D S=3.45)$ scores for the fear of catching COVID-19 $\left(\mathrm{t}_{\text {Welch }}(799.52)=-0.97\right.$, $p=0.331, \mathrm{~d}_{\text {Cohen }}=0.07$, CI99\% $\left.[-0.23-0.10]\right)$.

\section{Predictive Model}

Table 2 shows that the structural model has adequate adjustment indexes $(\chi 2=2075.93 ; \mathrm{df}=371 ; \mathrm{p}=0.000$;
RMSEA $=0.070$ [CI 90\% 0.067-0.073]; SRMR $=0.055$; $\mathrm{CFI}=0.95 ; \mathrm{TLI}=0.94)$ and the measurement models are adequately represented by their items. Figure 1 shows that the degree of concern about getting COVID-19 significantly influences the level of anxiety $(\beta=0.52 ; p<0.01)$, insomnia $(\beta=.44 ; \mathrm{p}<.01)$ and depression $(\beta=.50 ; \mathrm{p}<.01)$ experienced by university students.
Table 2 Structural model and measurement models

Fig. 1 Predictive model of fear of catching COVID-19

\begin{tabular}{|c|c|c|c|c|c|c|c|c|}
\hline \multicolumn{9}{|c|}{ Structural model } \\
\hline \multicolumn{2}{|l|}{$X^{2}$} & df & $\mathrm{p}$ & RMSEA & $90 \% \mathrm{CI}$ & SRMR & CFI & TLI \\
\hline \multicolumn{2}{|c|}{2075.93} & 371 & .000 & .070 & $.067-.073$ & .055 & .95 & .94 \\
\hline \multicolumn{9}{|c|}{ Measurement models } \\
\hline \multirow[t]{2}{*}{ Items } & \multicolumn{3}{|c|}{ Fear of catching COVID-19 } & Anxiety & Depression & & \multicolumn{2}{|l|}{ Insomnia } \\
\hline & \multicolumn{3}{|l|}{$\lambda$ (error) } & $\lambda$ (error) & $\lambda$ (error) & & \multicolumn{2}{|l|}{$\lambda$ (error) } \\
\hline 1 & \multicolumn{3}{|l|}{$.78(.39)$} & $.81(.34)$ & $.73(.47)$ & & \multicolumn{2}{|l|}{$.85(.28)$} \\
\hline 2 & \multicolumn{3}{|l|}{$.88(.22)$} & $.82(.33)$ & $.82(.33)$ & & \multicolumn{2}{|l|}{$.83(.32)$} \\
\hline 3 & \multicolumn{3}{|l|}{$.81(.34)$} & $.94(.12)$ & $.81(.35)$ & & \multicolumn{2}{|l|}{$.54(.71)$} \\
\hline 4 & \multicolumn{3}{|l|}{$.88(.22)$} & $.83(.31)$ & $.77(.41)$ & & \multicolumn{2}{|l|}{$.72(.48)$} \\
\hline 5 & \multicolumn{3}{|l|}{$.91(.18)$} & $.79(.38)$ & $.73(.47)$ & & \multicolumn{2}{|l|}{$.79(.38)$} \\
\hline 6 & \multicolumn{3}{|l|}{$.75(.44)$} & $.73(.46)$ & $.81(.34)$ & & \multicolumn{2}{|l|}{$.76(.42)$} \\
\hline \multicolumn{4}{|l|}{7} & $.82(.33)$ & $.76(.43)$ & & \multicolumn{2}{|l|}{$.81(.34)$} \\
\hline \multicolumn{4}{|l|}{8} & & $.77(.40)$ & & & \\
\hline \multicolumn{4}{|l|}{9} & & $.68(.53)$ & & & \\
\hline
\end{tabular}

Note: $\lambda$ : Factorial load

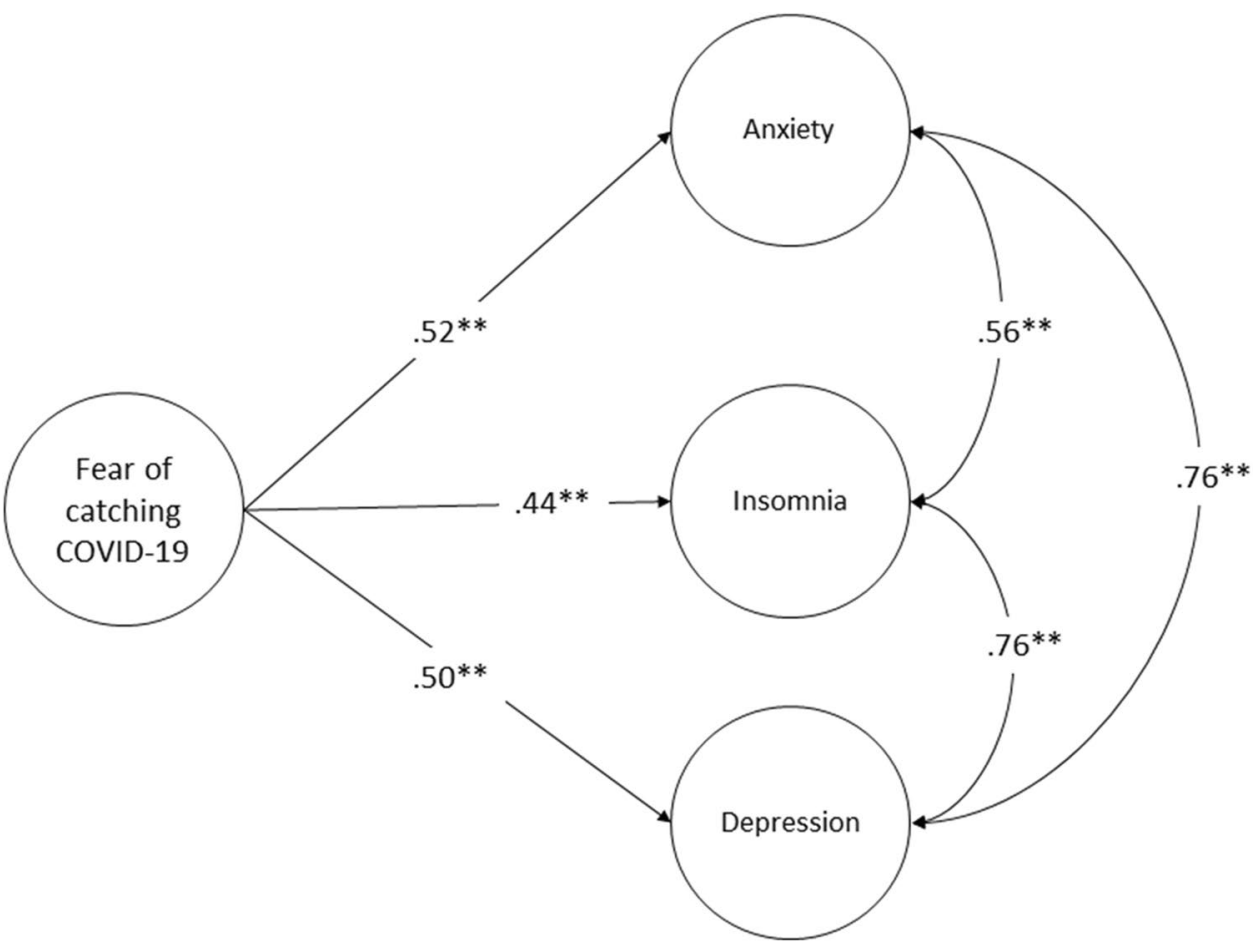




\section{Discussion}

The results of this study show that a notable percentage of university students present significant symptoms of anxiety (23\%), depression (24\%) and insomnia (32.9\%). It was found that the prevalence of anxiety is higher than that reported by Ge et al. (2020) and Cao et al. (2020) in China (12.4\% and $21.3 \%$ respectively) and it is also higher than the levels reported by Saraswathi et al. (2020) in India (21.2\%). However, it is lower than that found by Khan et al. (2020) in Bangladesh (33.3\%) and Cayo-Rojas et al. (2021) in Peru (47.4\%). Regarding the prevalence of depression, the present results are lower than those reported by Khan et al. (2020) and Saraswathi et al. (2020) in Bangladesh (46.9\%) and India (33.2\%), respectively. The prevalence of insomnia was found to be higher than that estimated by Ge et al. (2020) in China (16.8\%) and Scotta et al. (2021) in Argentina (23\%). It is worth noting that there are few studies that evaluate the prevalence of insomnia in the university population.

The variability observed concerning the different studies could be explained by the differences in the sample size used in the previous studies. The range of sample sizes varied between 217 (Saraswathi et al., 2020) and 7143 students (Cao et al., 2020). Also, it could be explained by the type of instruments used to measure the variables (Bukumiric et al., 2016; Guerra et al., 2016) and the cultural context to which the university students belong (Hofmann \& Hinton, 2014; Smith et al., 2016).

Regarding the level of fear of catching COVID-19 according to sex, it was found that there are no significant differences between men and women. This result differs from what was found in another study (Rodríguez-Hidalgo et al., 2020). This could be explained by the sample size and age range of the evaluated participants in each study. In the study by Rodríguez-Hidalgo et al. (2020) there is a higher proportion of women $(72 \%)$ than men $(28 \%)$ and the age range is wider (18-47 years). In contrast, in the present study the proportion of women $(58.4 \%)$ and men $(41.6 \%)$ was more balanced and the age range was smaller (18 to 35 years). Furthermore, it is important to mention that the present study corroborated the factorial invariance of the scale, to avoid a possible bias in the comparison of the scores.

The main result of this study shows that the concern about COVID-19 has a negative impact on some mental health indicators in university students. This result is consistent with previous studies that indicate that long periods of infectious epidemics can negatively affect the people's psychological states (Lee et al., 2007; Pappas et al., 2009; Wu et al., 2005a; Yang et al., 2021). Specifically, it was found that the concern about catching the virus explains
$52 \%$ of the anxiety symptoms and $50 \%$ of the depression symptoms experienced by undergraduate students. These symptoms could be explained by the negative consequences that getting COVID-19 would have on one's own health, their family's health, their educational progress and their professional future. Also, it could be related to the fear of being stigmatized by their social circle.

It was also found that the fear of catching the virus explains $44 \%$ of the symptoms of insomnia. This is because fear and constant worry cause a serious cognitive disturbance which affects the quality of sleep (Kalmbach et al., 2018). In addition, this result coincides with that found in an adult population (Kokou-kpolou et al., 2020; Voitsidis et al., 2020).

Regarding the limitations of this study, firstly, non-probabilistic sampling was used, which limits the generalizability of the results. Future studies should use representative samples to confirm the results. Second, only self-report measures were used, which can be affected by the participants' perception of social desirability. Thus future studies should use qualitative interviews or case studies to overcome this limitation. Third, a cross-sectional design was used, so the model should be studied using a longitudinal design in future studies in order to better understand the variables. Fourth, the model did not include variables such as cognitive flexibility (Pakenham et al., 2020), social support (Lee \& You, 2020), and knowledge about COVID-19 (Rodríguez-Rey et al., 2020) which could mediate the effect of concern about becoming infected on mental health indicators. Despite these limitations, this study provides a conceptual and statistical basis for a better understanding of the psychological impact of COVID-19 in the university population.

In conclusion, worrying about getting COVID-19 is a serious health problem since it influences the appearance of symptoms of anxiety, depression and insomnia. In addition, it was found that a significant percentage of university students present clinical symptoms of anxiety, depression and insomnia. Therefore, governments and universities should work together to provide timely and quality psychological services to address this public health problem.

Data availability The datasets generated during and analyzed during the current study are available from the corresponding author on reasonable request.

\section{Declarations}

Conflict of interest The authors state that they have no real, potential or apparent conflict of interest.

Ethical approval All procedures performed in the study were approved by the university's ethics committee and conformed to the requirements of the 1975 Declaration of Helsinki. 
Informed consent Informed consent was obtained from all participants included in the study.

\section{References}

Acharya, L., Jin, L., \& Collins, W. (2018). College life is stressful today-Emerging stressors and depressive symptoms in college students. Journal of American College Health, 66(7), 655-664. https://doi.org/10.1080/07448481.2018.1451869

Arora, A., Kumar, A., Alat, P., \& Sekhar, S. (2020). Understanding coronaphobia Alisha. Asian Journal of Psychiatry, 54, 102384. https://doi.org/10.1016/j.ajp.2020.102384

Auerbach, R., Mortier, P., Bruffaerts, R., Alonso, J., Benjet, C., Cuijpers, P., Demyttenaere, K., Ebert, D., Green, J., Murray, E., Nock, M., Pinder-amaker, S., Sampson, N., Stein, D., Vilagut, G., Zaslavsky, A., \& Kessler, R. (2019). Student Project : Prevalence and Distribution of Mental Disorders. Journal of Abnormal Psychology, 127(7), 623-638. https://doi.org/10.1037/abn0000362

Bastien, C. H., Vallières, A., \& Morin, C. M. (2001). Validation of the insomnia severity index as an outcome measure for insomnia research. Sleep Medicine, 2(4), 297-307. https://doi.org/10.1016/ S1389-9457(00)00065-4

Bukumiric, Z., Starcevic, V., Stanisavljevic, D., Marinkovic, J., Milic, N., Djukic-Dejanovic, S., Janjic, V., Corac, A., Ilic, A., Kostic, M., Nikolic, I., \& Trajkovic, G. (2016). Meta-analysis of the changes in correlations between depression instruments used in longitudinal studies. Journal of Affective Disorders, 190, 733743. https://doi.org/10.1016/j.jad.2015.10.054

Cao, W., Fang, Z., Hou, G., Han, M., Xu, X., \& Dong, J. (2020). The psychological impact of the COVID-19 epidemic on college students in China. Psychiatry Research Journal, 287, 112934. https:// doi.org/10.1016/j.psychres.2020.112934

Caycho-Rodríguez, T., Carbajal-León, C., Vilca, L. W., Heredia-Mongrut, J., \& Gallegos, M. (2020). COVID-19 y salud mental en policías peruanos: resultados preliminares. Acta Médica Peruana, 37(3), 396-398. https://doi.org/10.35663/amp.2020.373.1503

Caycho-Rodríguez, T., Ventura-León, J., \& Barboza-Palomino, M. (2021). Design and validation of a scale to measure worry for contagion of the COVID-19 (PRE-COVID-19). Enfermeria Clinica, 31(3), 175-183. https://doi.org/10.1016/j.enfcli.2020.10.034

Cayo-Rojas, C. F., Castro-Mena, M. J., Agramonte-Rosell, R. C., Aliaga-Mariñas, A. S., Ladera-Castañeda, M. I., CervantesGanoza, L. A., \& Cervantes-Liñán, L. C. (2021). Impact of COVID-19 Mandatory Social Isolation on the Development of Anxiety in Peruvian Dentistry Students: A Logistic Regression Analysis. Journal of International Society of Preventive \& Community Dentistry, 11(2), 222-229. https://doi.org/10.4103/jispcd. JISPCD_52_21

Chen, R., Liang, S., Peng, Y., Li, X., Chen, J., Tang, S., \& Zhao, J. (2020). Mental health status and change in living rhythms among college students in China during the COVID-19 pandemic: A large-scale survey. Journal of Psychosomatic Research, 137(August), 110219. https://doi.org/10.1016/j.jpsychores.2020. 110219

Essadek, A., \& Rabeyron, T. (2020). Mental health of French students during the Covid-19 pandemic. Journal of Affective Disorders, 277, 392-393. https://doi.org/10.1016/j.jad.2020.08.042

Fernandez-Mendoza, J., Rodriguez-Muñoz, A., Vela-Bueno, A., Olavarrieta-Bernardino, S., Calhoun, S. L., Bixler, E. O., \& Vgontzas, A. N. (2012). The Spanish version of the Insomnia Severity Index: A confirmatory factor analysis. Sleep Medicine, 13(2), 207-210. https://doi.org/10.1016/j.sleep.2011.06.019
García-Campayo, J., Zamorano, E., Ruiz, M. A., Pardo, A., PérezPáramo, M., López-Gómez, V., Freire, O., \& Rejas, J. (2010). Cultural adaptation into Spanish of the generalized anxiety disorder-7 (GAD-7) scale as a screening tool. Health Qual Life Outcomes, 8(8). https://doi.org/10.1186/1477-7525-8-8

Ge, F., Zhang, D., Wu, L., \& Mu, H. (2020). Predicting psychological state among chinese undergraduate students in the covid-19 epidemic: A longitudinal study using a machine learning. $\mathrm{Neu}$ ropsychiatric Disease and Treatment, 16, 2111-2118. https://doi. org/10.2147/NDT.S262004

Guerra, M., Prina, A. M., Ferri, C. P., Acosta, D., Gallardo, S., Huang, Y., Jacob, K. S., Jimenez-Velazquez, I. Z., Llibre Rodriguez, J. J., Liu, Z., Salas, A., Sosa, A. L., Williams, J. D., Uwakwe, R., \& Prince, M. (2016). A comparative cross-cultural study of the prevalence of late life depression in low and middle income countries. Journal of Affective Disorders, 190, 362-368. https://doi. org/10.1016/j.jad.2015.09.004

Hofmann, S. G., \& Hinton, D. E. (2014). Cross-cultural aspects of anxiety disorders. Current Psychiatry Reports, 16(6). https://doi. org/10.1007/s11920-014-0450-3

Holmes, E. A., O'Connor, R. C., Perry, V. H., Tracey, I., Wessely, S., Arseneault, L., Ballard, C., Christensen, H., Cohen Silver, R., Everall, I., Ford, T., John, A., Kabir, T., King, K., Madan, I., Michie, S., Przybylski, A. K., Shafran, R., Sweeney, A., ... Bullmore, E. (2020). Multidisciplinary research priorities for the COVID-19 pandemic: a call for action for mental health science. The Lancet Psychiatry, 7(6), 547-560. https://doi.org/10.1016/ S2215-0366(20)30168-1

Hu, Y., Chen, Y., Zheng, Y., You, C., Tan, J., Hu, L., Zhang, Z., \& Ding, L. (2020). Brain, Behavior, and Immunity Factors related to mental health of inpatients with COVID-19 in Wuhan, China. Brain Behavior and Immunity, 89(May), 587-593. https://doi.org/ 10.1016/j.bbi.2020.07.016

Husky, M. M., Kovess-Masfety, V., \& Swendsen, J. D. (2020). Stress and anxiety among university students in France during Covid-19 mandatory confinement. Comprehensive Psychiatry, 102, 152191. https://doi.org/10.1016/j.comppsych.2020.152191

Jorgensen, T. D., Pornprasertmanit, S., Schoemann, A. M., \& Rosseel, Y. (2018). semTools: Useful tools for structural equation modeling. $R$ package version $0.5-1$. https://cran.r-project.org/packa ge $=$ semTools

Kalmbach, D. A., Cuamatzi-Castelan, A. S., Tonnu, C. V., Tran, K. M., Anderson, J. R., Roth, T., \& Drake, C. L. (2018). Hyperarousal and sleep reactivity in insomnia: Current insights. Nature and Science of Sleep, 10, 193-201. https://doi.org/10.2147/NSS.S138823

Karing, C. (2021). Prevalence and predictors of anxiety, depression and stress among university students during the period of the first lockdown in Germany. Journal of Affective Disorders Reports. https://doi.org/10.1016/j.jadr.2021.100174

Kecojevic, A., Basch, C. H., Sullivan, M., \& Davi, N. K. (2020). The impact of the COVID-19 epidemic on mental health of undergraduate students in New Jersey, cross-sectional study. PLOS ONE, 15(9), e0239696. https://doi.org/10.1371/journal.pone.0239696

Khan, A. H., Sultana, M. S., Hossain, S., Hasan, M. T., Ahmed, H. U., \& Sikder, M. T. (2020). Journal of A ff ective Disorders The impact of COVID-19 pandemic on mental health \& wellbeing among home-quarantined Bangladeshi students: A cross-sectional pilot study. Journal of Affective Disorders, 277(May), 121-128. https://doi.org/10.1016/j.jad.2020.07.135

Kline, R. B. (2015). Principles and practice of structural equation modeling (4th ed.). The Guilford Press.

Kokou-kpolou, C. K., Megalakaki, O., Laimou, D., \& Kousouri, M. (2020). factors in French population. Psychiatry Research, 290, 113128. https://doi.org/10.1016/j.psychres.2020.113128

Korkeila, J., Lehtinen, V., Bijl, R., Dalgard, O. S., Kovess, V., Morgan, A., \& Salize, H. J. (2003). Review Article: Establishing a 
set of mental health indicators for Europe. Scandinavian Journal of Public Health, 31(6), 451-459. https://doi.org/10.1080/14034 940210165208

Lee, A. M., Wong, J. G. W. S., McAlonan, G. M., Cheung, V., Cheung, C., Sham, P. C., Chu, N. M., Wong, P. C., Tsang, K. W. T., \& Chua, S. E. (2007). Stress and psychological distress among SARS survivors 1 year after the outbreak. Canadian Journal of Psychiatry, 52(4), 233-240. https://doi.org/10.1177/0706743707 05200405

Lee, M., \& You, M. (2020). Psychological and behavioral responses in South Korea during the early stages of coronavirus disease 2019 (COVID-19). International Journal of Environmental Research and Public Health, 17(9), 2977. https://doi.org/10.3390/ijerp h17092977

Lin, Y. H., Chiang, T. W., \& Lin, Y. L. (2020). Increased internet searches for insomnia as an indicator of global mental health during the COVID-19 pandemic: Multinational longitudinal study. Journal of Medical Internet Research, 22(9), 1-7. https://doi.org/ $10.2196 / 22181$

Main, A., Zhou, Q., Ma, Y., Luecken, L. J., \& Liu, X. (2011). Relations of sars-related stressors and coping to chinese college students' psychological adjustment during the 2003 beijing sars epidemic. Journal of Counseling Psychology, 58(3), 410-423. https://doi. org/10.1037/a0023632

Manea, L., Gilbody, S., \& McMillan, D. (2012). Optimal cut-off score for diagnosing depression with the Patient Health Questionnaire (PHQ-9): A meta-analysis. Canadian Medical Association Journal, 184(3), 191-196. https://doi.org/10.1503/cmaj.112004

Morin, C. M., Belleville, G., Bélanger, L., \& Ivers, H. (2011). The Insomnia Severity Index: Psychometric Indicators to Detect Insomnia Cases and Evaluate Treatment Response. Sleep, 34(5), 601-608. https://doi.org/10.1093/sleep/34.5.601

Muller, A. E., Hafstad, E. V., Himmels, J. P. W., Smedslund, G., Flottorp, S., Stensland, S. O., Stroobants, S., Van de Velde, S., \& Vist, G. E. (2020). The mental health impact of the covid-19 pandemic on healthcare workers, and interventions to help them: A rapid systematic review. Psychiatry Research, 293(August), 113441. https://doi.org/10.1016/j.psychres.2020.113441

Pakenham, K. I., Landi, G., Boccolini, G., Furlani, A., Grandi, S., \& Tossani, E. (2020). The moderating roles of psychological flexibility and inflexibility on the mental health impacts of COVID-19 pandemic and lockdown in Italy. Journal of Contextual Behavioral Science, 17(July), 109-118. https://doi.org/10.1016/j.jcbs. 2020.07.003

Pappas, G., Kiriaze, I. J., Giannakis, P., \& Falagas, M. E. (2009). Psychosocial consequences of infectious diseases. Clinical Microbiology and Infection, 15(8), 743-747. https://doi.org/10.1111/j. 1469-0691.2009.02947.x

Patil, I. (2018). ggstatsplot: "ggplot2" Based Plots with Statistical Details. https://cran.r-project.org/web/packages/ggstatsplot/index. html

Pigeon, W. R., Bishop, T. M., \& Krueger, K. M. (2017). Insomnia as a Precipitating Factor in New Onset Mental Illness: a Systematic Review of Recent Findings. Current Psychiatry Reports, 19(8). https://doi.org/10.1007/s11920-017-0802-x

$\mathrm{R}$ Core Team. (2019). A language and environment for statistical computing ( $\mathrm{R}$ version 3.6.1). R Foundation for Statistical Computing. http://www.r-project.org/

Rickman, P. P. (1964). Human Experimentatio: Code of ethics of the world medical association. Declaration of Helsinki. British Medical Journal, 2(5402), 177. https://doi.org/10.1136/bmj.2.5402.177

Rodríguez-Hidalgo, A. J., Pantaleón, Y., Dios, I., \& Falla, D. (2020). Fear of COVID-19, Stress, and Anxiety in University Undergraduate Students: A Predictive Model for Depression. Frontiers in Psychiatry, 11(591797). https://doi.org/10.3389/fpsyg.2020.591797
Rodríguez-Rey, R., Garrido-Hernansaiz, H., \& Collado, S. (2020). Psychological Impact and Associated Factors During the Initial Stage of the Coronavirus (COVID-19) Pandemic Among the General Population in Spain. Frontiers in Psychology, 11(June), 1540. https://doi.org/10.3389/fpsyg.2020.01540

Rosseel, Y. (2012). lavaan: An R package for structural equation modeling. Journal of Statistical Software, 48(2), 1-36. https://doi.org/ 10.18637 /jss.v048.i02

RStudio Team. (2018). RStudio: Integrated Development Environment for R. RStudio, Inc. http://www.rstudio.com/

Saraswathi, I., Saikarthik, J., Kumar, K. S., Srinivasan, K. M., Ardhanaari, M., \& Gunapriya, R. (2020). Impact of COVID-19 outbreak on the mental health status of undergraduate medical students in a COVID-19 treating medical college: A prospective longitudinal study. Peer J, 8, e10164. https://doi.org/10.7717/peerj.10164

Schumacker, R. E., \& Lomax, R. G. (2015). A Beginner's Guide to Structural Equation Modeling: Fourth Edition (4th ed.). Routledge.

Scotta, A. V., Cortez, M. V., \& Miranda, A. R. (2021). Insomnia is associated with worry, cognitive avoidance and low academic engagement in Argentinian university students during the COVID19 social isolation. Psychology, Health and Medicine, 1-16. https://doi.org/10.1080/13548506.2020.1869796

Sivertsen, B., Vedaa, Ø., Harvey, A. G., Glozier, N., Pallesen, S., Aarø, L. E., Lønning, K. J., \& Hysing, M. (2018). Sleep patterns and insomnia in young adults: A national survey of Norwegian university students. Journal of Sleep Research, 28(2), 1-10. https:// doi.org/10.1111/jsr. 12790

Smith, P. B., Easterbrook, M. J., Celikkol, G. C., Chen, S. X., Ping, H., \& Rizwan, M. (2016). Cultural Variations in the Relationship Between Anger Coping Styles, Depression, and Life Satisfaction. Journal of Cross-Cultural Psychology, 47(3), 441-456. https:// doi.org/10.1177/0022022115620488

Spitzer, R. L., Kroenke, K., \& Williams, J. B. W. (1999). Validation and utility of a self-report version of PRIME-MD: the PHQ primary care study. Primary Care Evaluation of Mental Disorders. Patient Health Questionnaire. JAMA, 282(18), 1737-1744. https://doi.org/ 10.1001/jama.282.18.1737

Spitzer, R. L., Kroenke, K., Williams, J. W., \& Löwe, B. (2006). A brief measure for assessing generalized anxiety disorder: The GAD-7. Archives of Internal Medicine, 166(10), 1092-1097. https://doi. org/10.1001/archinte.166.10.1092

Taylor, S. (2019). The psychology of pandemics: Preparing for the next global outbreak of infectious disease. Cambridge Scholars Publishing.

Voitsidis, P., Gliatas, I., Bairachtari, V., Papadopoulou, K., Papageorgiou, G., Parlapani, E., Syngelakis, M., Holeva, V., \& Diakogiannis, I. (2020). Letter to the Editor Insomnia during the COVID-19 pandemic in a Greek population. Psychiatry Research, 289(May), 113076. https://doi.org/10.1016/j.psychres.2020.113076

Wang, C., \& Zhao, H. (2020). The Impact of COVID-19 on Anxiety in Chinese University Students. Frontiers in Psychology, 11(January), 1-8. https://doi.org/10.3389/fpsyg.2020.01168

Wang, C., Pan, R., Wan, X., Tan, Y., Xu, L., Ho, C. S., \& Ho, R. C. (2020). Immediate Psychological Responses and Associated Factors during the Initial Stage of the 2019 Coronavirus Disease (COVID-19) Epidemic among the General Population in China. International Journal of Environmental Research and Public Health, 17(5), 1729. https://doi.org/10.3390/ijerph17051729

World Health Organization. (2020). Coronavirus Disease (COVID-19) Dashboard. Retrieved June 24, 2021 from https://covid19.who.int/

World Medical Association. (2013). World Medical Association Declaration of Helsinki Ethical Principles for Medical Research Involving Human Subjects. Clinical Review \& Education Special, 27(20), 2191-2194. https://doi.org/10.1001/jama.292.11.1359 
Wu, K. K., Chan, S. K., \& Ma, T. M. (2005a). Posttraumatic stress, anxiety, and depression in survivors of severe acute respiratory syndrome (SARS). Journal of Traumatic Stress, 18(1), 39-42. https://doi.org/10.1002/jts.20004

Wu, K. K., Chan, S. K., \& Ma, T. M. (2005b). Posttraumatic stress after SARS. Emerging Infectious Diseases, 11(8), 1297-1300. https:// doi.org/10.3201/eid1108.041083

Xiong, J., Lipsitz, O., Nasri, F., Lui, L. M. W., Gill, H., \& Phan, L. (2020). Impact of COVID-19 pandemic on mental health in the general population: A systematic review. Journal of Affective Disorders, 277(August), 55-64. https://doi.org/10.1016/j.jad.2020. 08.001

Yang, C., Chen, A., \& Chen, Y. (2021). College students'stress and health in the COVID-19 pandemic: The role of academic workload, separation from school, and fears of contagion. PLOS ONE, 16(2), e0246676. https://doi.org/10.1371/journal.pone.0246676
Zhong, Q., Gelaye, B., Fann, J. R., Sanchez, S. E., \& Williams, M. A. (2014). Cross-cultural validity of the Spanish version of PHQ-9 among pregnant Peruvian women: A Rasch item response theory analysis. Journal of Affective Disorders, 158, 148-153. https:// doi.org/10.1016/j.jad.2014.02.012

Zivin, K., Eisenberg, D., Gollust, S. E., \& Golberstein, E. (2009). Persistence of mental health problems and needs in a college student population. Journal of Affective Disorders, 117(3), 180-185. https://doi.org/10.1016/j.jad.2009.01.001

Publisher's note Springer Nature remains neutral with regard to jurisdictional claims in published maps and institutional affiliations. 